\title{
Inhibition of Adipogenesis by Ghrelin
}

\author{
Weizhen Zhang, Lili Zhao, Theodore R. Lin, Biaoxin Chai, Yongyi Fan, \\ Ira Gantz and Michael W. Mulholland*
}

\author{
Department of Surgery, Michigan Gastrointestinal Peptide Center, University of Michigan, Ann \\ Arbor, Michigan 48109
}

Submitted September 10, 2003; Revised March 1, 2004; Accepted March 3, 2004

Monitoring Editor: Guido Guidotti

\begin{abstract}
Ghrelin, a novel gastric hormone, regulates food intake and energy metabolism via central mechanisms. The peripheral effect of ghrelin on adiposity is poorly understood. We established a stable 3T3-L1 cell line expressing ghrelin to study the direct effect of ghrelin on adipogenesis. Cells overexpressing ghrelin demonstrate significantly attenuated differentiation of preadipocytes into adipocytes. Expression of peroxisome proliferator-activator receptor- $\gamma$ is significantly inhibited as demonstrated by decrease of peroxisome proliferator-activator receptor- $\gamma$ mRNA and protein. Both ghrelin overexpression and exogenous ghrelin stimulate cell proliferation. Phosphorylation of mitogen-activated protein kinase is increased after treatment of cells with ghrelin. Ghrelin binding activity is demonstrated in both native and ghrelinoverexpressing 3T3-L1 cells by radiolabeled ghrelin, although reverse transcription-polymerase chain reaction with the primer sequence of the previously identified ghrelin receptor subtypes detected no signal. Our results demonstrate that ghrelin inhibits adipogenesis by stimulation of cell proliferation via the mediation of a ghrelin receptor, likely a novel unidentified subtype.
\end{abstract}

\section{INTRODUCTION}

Ghrelin, a novel 28-amino acid peptide, was initially purified from rat stomach (Kojima et al., 1999) and localized to gastric oxyntic glands (Date et al., 2000), the hypothalamus (Kojima et al., 1999; Cowley et al., 2003), and kidney (Mori et al., 2000). Ghrelin receptor, also known as growth hormone secretagogue receptor, contains seven transmembrane (TM) domains and belongs to a family of $\mathrm{G}$ protein-coupled receptors (Howard et al., 1996; McKee et al., 1997). Ghrelin receptors are widely distributed among both central and peripheral tissues, including pituitary gland, hypothalamus, pancreas, stomach, and intestine (Howard et al., 1996; Date et al., 2000, 2002). cDNAs for human, rat, mouse, and swine ghrelin receptor have been sequenced previously (Howard et al., 1996; McKee et al., 1997). Two types of ghrelin receptor cDNA have been identified: type 1a, encoding a functional protein containing seven TM domains; and type $1 \mathrm{~b}$, encoding a protein containing TM-1 through 5 with no measurable functional activity. In addition, recent studies suggest the existence of another unidentified subtype of ghrelin receptor (Baldanzi et al., 2002).

In common with synthetic growth hormone secretagogue, ghrelin causes growth hormone release in vivo from humans and rats after either peripheral or central administration and in vitro from primary cultured pituitary cells (Kojima et al., 1999; Takaya et al., 2000; Wren et al., 2000). Ghrelin also plays an important role in the control of food intake and energy metabolism. Ghrelin peptide secretion and mRNA expression are increased by weight loss, restriction of caloric intake and insulin-induced hypoglycemia (Tschop et al., 2000; Lee et al., 2002;

Article published online ahead of print. Mol. Biol. Cell 10.1091/ mbc.E03-09-0657. Article and publication date are available at www.molbiolcell.org/cgi/doi/10.1091/mbc.E03-09-0657.

*Corresponding author. E-mail address: micham@umich.edu.
Cummings et al., 2001; Toshinai et al., 2001). In rats, ghrelin has been found to stimulate food intake (Nakazato et al., 2001; Wren et al., 2000), to induce adiposity (Tschop et al., 2000) and to increase body weight (Tschop et al., 2000; Nakazato et al., 2001). Administration of ghrelin antibody or ghrelin receptor antagonists prevents ghrelin-induced positive energy balance (Nakazato et al., 2001). Weight gain and adiposity caused by ghrelin are independent of its ability to modulate growth hormone secretion (Nakazato et al., 2001; Tschop et al., 2000; Wren et al., 2000).

Although ghrelin is secreted from the stomach and circulates in the blood, the orexigenic effect of ghrelin has been reported to be mediated by the hypothalamic circuit in the central nervous system (Tschop et al., 2000; Wren et al., 2000; Horvath et al., 2001; Nakazato et al., 2001; Cowley et al., 2003). Direct effects of ghrelin on peripheral tissues that contribute to the regulation of body weight and energy homeostasis are controversial. Banks et al. (2002) reported that the quantity of ghrelin transport in the blood-to-brain direction is negligible, suggesting that the orexigenic effect induced by systemic ghrelin may be mediated by a peripheral mechanism. Using in vitro culture of rat preadipocytes, Choi et al. (2003) reported that ghrelin stimulates adipogenesis via activation of ghrelin receptor subtype 1a. In contrast, Ott et al. (2002) demonstrated no direct effect of ghrelin on adipogenesis by using a well-characterized brown adipocyte model, even though ghrelin directly suppressed expression of adiponectin, an adipokine involved in the pathogenesis of insulin resistance and obesity. Because ghrelin is quickly degraded in vitro, it is difficult to study its effect on adipogenesis where long-term treatment of ghrelin is required.

A stable preadipocyte 3T3 L1 cell line overexpressing ghrelin was established to investigate the effect of ghrelin on adipogenesis in vitro. We report here that 1) overexpression of ghrelin in 3T3 L1 cells inhibits the differentiation of preadipocytes into adipocytes; 2 ) ghrelin stimulates cell proliferation; 3) ghrelin up-regulates mitogen-activated protein 
(MAP) kinase; 4) cells overexpressing ghrelin demonstrate decreased peroxisome proliferator-activator receptor (PPAR)- $\gamma$ mRNA and protein expression during differentiation; and 5) the effects of ghrelin are mediated by a ghrelin receptor, likely a novel unidentified subtype.

\section{MATERIALS AND METHODS}

\section{Generation of Ghrelin Plasmid by Reverse Transcription- Polymerase Chain Reaction (RT-PCR)}

Rat ghrelin was generated from gastric RNA by RT-PCR by using oligonucleotides generated from published sequences. Restriction sites HindIII and EcoR I were incorporated into primers. The sequences of ghrelin primers were sense, CCCAAGCTTAGGCCATGGTGTCTTC, and antisense, CCGGAATTCCAGTGGTTACTTGTT.

After the RT-PCR product was matched to the published sequence by sequencing analysis, ghrelin cDNA was excised, purified, and then cloned into the pcDNA 3.1 vector. Ghrelin plasmid was amplified in $\mathrm{DH} 5 \alpha$ and purified using the Maxi-pre kit from QIAGEN (Valencia, CA).

\section{Stable Cell Transfection}

Mouse 3T3-L1s were maintained in DMEM containing 10\% fetal calf serum, $1 \%$ penicillin-streptomycin, $1 \%$ sodium pyruvate, and $1 \%$ glutamine. Cells $\left(1.5 \times 10^{6}\right)$ were plated, and vectors (pcDNA3.1) and ghrelin constructs were transfected into cells by Lipofectamine (Invitrogen, Carlsbad, CA). Cells expressing ghrelin constructs were selected with $800 \mu \mathrm{g} / \mathrm{ml}$ neomycin. Stable cell lines were maintained with $400 \mu \mathrm{g} / \mathrm{ml}$ neomycin. Ghrelin expression was verified by 1) PCR with T7 primer and ghrelin antisense primer; 2) immunostaining with specific antibody against ghrelin (Phoenix Pharmaceuticals, Belmont, CA); and 3) radioimmunoassay (RIA) with a specific rat ghrelin RIA kit (Phoenix Pharmaceuticals)

\section{Differentiation of $3 T 3$ L1 Preadipocytes}

Mouse 3T3-L1 cells were grown and induced to differentiate as described previously (Weiss et al., 1980). Briefly, cells were grown to confluence in standard medium (DMEM supplemented with $10 \%$ fetal bovine serum). At confluence, cells were induced to differentiate by addition of insulin $(1 \mu \mathrm{g} /$ $\mathrm{ml})$, dexamethasone $(1 \mu \mathrm{M})$, and isobutylmethylxanthine $(0.5 \mathrm{mM})$ to standard medium for $4 \mathrm{~d}$. Cells were maintained for four additional days in standard medium with insulin. Cells were then cultured in standard medium without insulin for the remaining time. By using this protocol, $>95 \%$ of the cells began to acquire adipocyte morphology by 3-4 $\mathrm{d}$ and reached full differentiation by $10-12 \mathrm{~d}$. Fully differentiated adipocytes were identified by the characteristic morphology of multilocular fat droplets, which stained red by Oil Red-O solution as described previously (Ross et al., 2000).

\section{5-Bromo-2-deoxyuridine (BrdU) Incorporation}

Native cells, cells expressing pcDNA3.1 or ghrelin-expressing cells $\left(1 \times 10^{5}\right)$ were seeded onto a six-well dish containing coverslips. pcDNA 3.1- and ghrelin-expressing cells were labeled with $10 \mu \mathrm{M}$ BrdU for $24 \mathrm{~h}$. Native cells were treated with $10^{-6} \mathrm{M}$ exogenous ghrelin (Phoenix Pharmaceuticals) and labeled with $10 \mu \mathrm{M}$ BrdU in serum-free media for $24 \mathrm{~h}$. Samples were stained with $0.5 \mu \mathrm{g} / \mathrm{ml}$ antibodies against BrdU (Roche Diagnostics, Indianapolis, IN), and fluorescein isothiocyanate-conjugated antibody (1:50; Santa Cruz Biotechnology, Santa Cruz, CA). Total cell population was determined by 4,6-diamidino-2-phenylindole staining. BrdU-positive cells were counted under the microscope. For cell count assay, $1 \times 10^{5}$ cells were plated onto a $10-\mathrm{cm}$ dish. Forty-eight hours later, cells were harvested and counted.

\section{Flow Cytometry}

Cultured cells were harvested using trypsin/EDTA and washed twice with phosphate-buffered saline (PBS). Aliquots of $2 \times 10^{6}$ cells were centrifuged, fixed in $70 \%$ ethanol, stained with $500 \mu \mathrm{l}$ of propidium iodide (PI) solution $(100 \mu \mathrm{g} / \mathrm{ml}$ RNase and $50 \mu \mathrm{g} / \mathrm{ml}$ PI in $1 \times$ PBS $)$. Labeled cells were analyzed using a BD Biosciences FACSCalibur cell analyzer at $488 \mathrm{~nm}$. Fluorescence was measured at $650 \mathrm{~nm}$ for PI. Data were analyzed using Modfit software. DNA histograms were deconvoluted, and percentage of cells in each phase of cell cycle was calculated and expressed as mean \pm SEM.

\section{Western Blot Analysis}

Cultured cells were washed with cold PBS and harvested at the time indicated. Cells were lysed in radioimmunoprecipitation assay buffer $(1 \times \mathrm{PBS}, 1 \%$ NP-40, $0.5 \%$ sodium deoxycholate, $0.1 \%$ SDS). One tablet of protease inhibitor cocktail (Roche Diagnostics) and $1 \mathrm{mM}$ phenylmethylsulfonyl fluoride were added to $10 \mathrm{ml}$ of radioimmunoprecipitation assay buffer right before lysing the cells. Total protein was assayed with bicinchoninic acid assay kit (Pierce Chemical, Rockford, IL). Then, 50-250 $\mu \mathrm{g}$ of total protein was loaded onto a $7.5-10 \%$ denaturing gel. Proteins were transferred to polyvinylidene difluo- ride membrane for analysis. Phospho-specific and nonphospho-MAP kinase, and PPAR- $\gamma$ were detected with polyclonal anti-phospho-, or anti-nonphospho-MAP kinase antibodies (1:1000; Signal Transduction, Boston, MA) and PPAR- $\gamma$ antibodies (1:200; Santa Cruz Biotechnology).

\section{$R T-P C R$}

Total RNA was isolated from cultured 3T3-L1 cells by using RNeasy mini kit (QIAGEN) according to the manufacturer's directions. Single strand cDNA synthesis was performed as follows: $30 \mu \mathrm{l}$ of reverse transcription mixture contained $1 \mu \mathrm{g}$ of DNase I pretreated total RNA, $0.75 \mu \mathrm{g}$ of oligo $\mathrm{d}(\mathrm{T})$ primer, $6 \mu \mathrm{l}$ of $5 \times \mathrm{RT}$ buffer, $10 \mathrm{mM}$ dithiothreitol, $0.5 \mathrm{mM}$ deoxynucleotides, $50 \mathrm{U}$ of RNase inhibitor, and $240 \mathrm{U}$ of reverse transcriptase (Invitrogen). The RT reaction was carried out at $40^{\circ} \mathrm{C}$ for $70 \mathrm{~min}$ followed by heat inactivation at $95^{\circ} \mathrm{C}$ for $3 \mathrm{~min}$. PCR primers used for ghrelin receptor mRNA or PPAR- $\gamma 2$ mRNA detection were deduced from published sequences. The nucleotide sequences of sense and antisense primers with the expected product size are as follows: ghrelin receptor: 1) ACC TCC TCT GCA AAC TCT TCC (sense, bp 585-604) and CAC CCG TAC TTC TTG GAC AT (antisense, bp 1184-1165) 599-bp product or 2) TCC GAT CTG CTC ATC TTC CT (sense, bp 270-289) and CAG CTC TCG CTG ACA AAC TG (antisense, bp 385-366), 116-base pair product, or 3) TCC GAT CTG CTC ATC TTC CT (sense, bp 270-289) and GGA AGC AGA TGG CGA AGT AG (antisense, bp 450-431), 181-base pair product, or 4) GCT GAG CGT CGA GCG CTA CTT CG (sense, bp 405-427) GTT GCA GTA CTG GCT GAT CTG AGC (antisense, bp 2943-2920), 511-base pair product; PPAR- $\gamma 2$ : ATG GGT GAA ACT CTG GGA GAT TCT (sense, bp 46-69), CAT CCT TCA CAA GCA TGA ACT CCA (antisense, bp 498-521) 476-base pair product; and $\beta$-actin: AAA TCG TGC GTG ACA TCA AA(sense, bp 700-719) and AAG GAA GGC TGG AAA AGA GC (antisense, bp 858-877), 178-base pair product.

The cDNAs for ghrelin receptor and PPAR- $\gamma 2$ was amplified by RT-PCR. PCR was performed using Ampli Taq Polymerase (Roche Diagnostics). PCR products were visualized by $1.5 \%$ agarose gel electrophoresis. For negative controls, PCR reactions were performed for the primer pairs in the absence of transcript. Total RNA from hypothalamus was used as positive control for ghrelin receptor.

\section{Receptor Binding Assay}

Binding experiments were performed on whole cells by using conditions described previously (Yang et al., 2000). Twelve hours before the experiments, $3 \times 10^{5}$ cells were plated on 24-well plates. Before initiating binding experiments, cells were washed twice with minimal essential medium. Cells were then incubated with various concentrations of ghrelin (rat) or des-octanoyl ghrelin (rat) containing $0.2 \%$ bovine serum albumin and either $1 \times 10^{5} \mathrm{cpm}$ of ${ }^{125} \mathrm{I}$-ghrelin (rat) or ${ }^{125} \mathrm{I}$-des-octanoyl ghrelin (rat). After 1-h incubation, the cells were again washed twice with minimal essential medium, and the experiment terminated by lysing the cells with $0.1 \mathrm{~N} \mathrm{NaOH}, 1 \%$ Triton X-100. Radioactivity present in the lysate was quantified using an analytical gammacounter. Nonspecific binding was determined by measuring the amount of ${ }^{125} \mathrm{I}$ label remaining bound in the presence of $4 \times 10^{-6} \mathrm{M}$ unlabeled ligand, and specific binding was obtained by subtracting nonspecific bound radioactivity from total bound radioactivity. Data were analyzed using GraphPad Prism (GraphPad Software, San Diego, CA). $K_{\mathrm{i}}$ values were derived from $\mathrm{IC}_{50}$ value according to the equation $K_{\mathrm{i}}=\mathrm{IC}_{50}-$ [radioligand], and receptor density was calculated using the equation $B_{\max }=\mathrm{B}_{\mathrm{o}} \times \mathrm{IC}_{50} /$ [radioligand] (DeBlasi et al., 1989). All values are means \pm SEM determined from three independent experiments.

\section{RESULTS}

\section{Stable Cell Line Overexpressing Ghrelin}

The 3T3 L1 cell line stably transfected with ghrelin plasmid was established and maintained in medium containing 400 $\mu \mathrm{g} / \mathrm{ml}$ neomycin. Because native 3T3 L1 cells express endogenous ghrelin, we used a sense primer derived from the T7 promoter of pcDNA3.1 and an antisense primer derived from the ghrelin gene to demonstrate the successful transfection of the pcDNA3.1-ghrelin construct. mRNA containing the sequence of ghrelin pcDNA 3.1 plasmid was demonstrated only in cells transfected with pcDNA3.1-ghrelin construct, but not in native 3T3 L1 cells or cells transfected with pcDNA3.1 (Figure 1A). Overexpression of ghrelin protein was demonstrated in the cytoplasm of cells by immunostaining (Figure 1B). As shown in Figure 1C, increased concentration of ghrelin immunoreactivity in the cultured medium harvested from cells transfected with pcDNA3.1ghrelin construct was demonstrated to be significant com- 
A

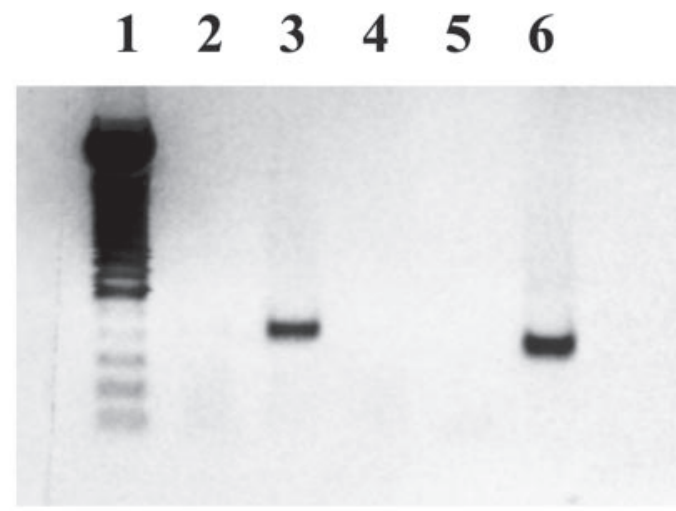

B
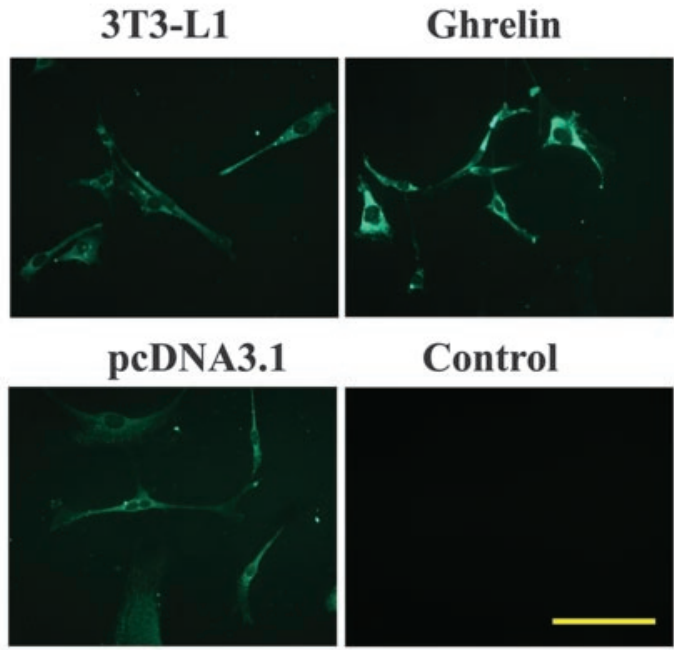

Control

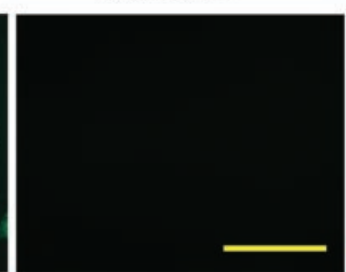

C

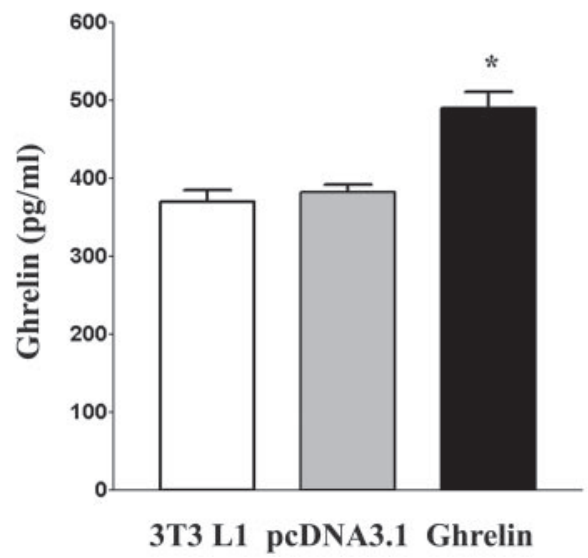

Figure 1. Expression of ghrelin in cells transfected with pcDNA3.1 containing ghrelin cDNA. (A) Expression of ghrelin mRNA. Total RNA was extracted from stable cell lines transfected with pcDNA3.1 or pcDNA3.1 containing ghrelin cDNAs. RT-PCR was performed using the T7 primer and the ghrelin antisense primer as indicated in the text. Lane 1, markers; lane 2, cells transfected with pcDNA3.1; lane 3, cells overexpressing ghrelin; lane 4, RT negative control; lane 5, PCR negative control; and lane 6, RT-PCR product from hypothalamus by using ghrelin sense and antisense primers. (B) Expression of ghrelin protein. Ghrelin immunoreactivity was detected by immunofluorescence in cell cultures. Control cultures lacking specific primary antibody incubation showed no significant staining. (C) Secretion of ghrelin. Five million of native 3T3 L1 cells, or cells transfected with pcDNA3.1, or cells transfected with ghrelin were cultured for $6 \mathrm{~h}$. Culture media were harvested and assayed for ghrelin by using a specific rat ghrelin RIA kit. Results are expressed as mean \pm SEM; $n=3$. * indicates $p<0.01$ as compared with native 3T3 L1 cells or cells transfected with pcDNA3.1.

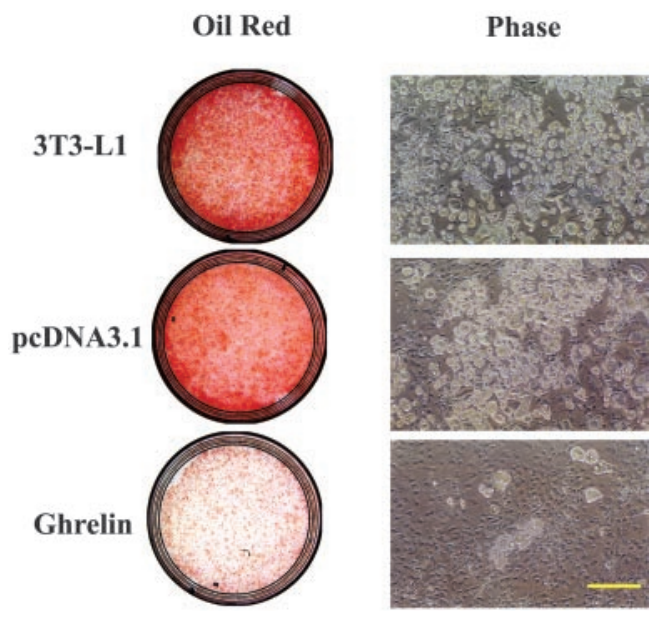

Figure 2. Overexpression of ghrelin inhibits adipogenesis. Native, pcDNA3.1 vector-expressing, and ghrelin-overexpressing cells were allowed to transform from preadipocytes to adipocytes for $10 \mathrm{~d}$. Cells were fixed and stained of Oil Red, a specific stain for fat cells. Data are representative of five separate experiments. Bar, $100 \mu \mathrm{m}$.

pared with those in native 3T3 L1 cells or cells transfected with pcDNA3.1 $(\mathrm{p}<0.01)$.

\section{Inhibition of Adipogenesis}

To investigate whether ghrelin affects preadipocyte differentiation, we used the 3T3-L1 cell line stably overexpressing ghrelin and assayed its ability to differentiate into adipocytes. Cells transfected with pcDNA 3.1, which was used as a control, differentiated into adipocytes as indicated by the appearance of the microscopic pattern of multilocular fat droplets. These fat droplets occurred as early as day 4 and stained positive by Oil Red-O staining, indicating the accumulation of intracellular triglycerides. In contrast, cells overexpressing ghrelin demonstrated few fat droplets even at $2 \mathrm{wk}$ (Figure 2).

\section{Mitotic Effect of Ghrelin}

Because cell growth and differentiation are usually mutually exclusive and because preadipocytes usually undergo growth arrest before differentiation, we assayed the effect of ghrelin on cell growth. Cell count experiments demonstrated that cells overexpressing ghrelin proliferate $2.4 \pm$ 0.5 -fold ( $\mathrm{p}<0.05, \mathrm{n}=6$ ) faster than control cells transfected with the vector pcDNA 3.1. To further characterize the mitotic effect of ghrelin, we used both BrdU incorporation and flow cytometry to identify cells undergoing proliferation. As shown in Figure 3A, cells overexpressing ghrelin demonstrated a significantly higher percentage of BrdU incorporation than cells expressing the vector pcDNA $3.1(n=4, p<$ 0.05 ). When native 3T3-L1 cells were treated with exogenous ghrelin, the percentage of BrdU incorporation significantly increased to $51 \pm 9$ from $39 \pm 8 \%$ in control cells $(n=6, p<$ 0.05) (Figure 3b). In agreement with the BrdU data, flow cytometry analysis showed that $25 \pm 3 \%$ of cells overexpressing ghrelin were actively proliferating, whereas only $9 \pm 3 \%$ of cells expressing the vector were in $\mathrm{S}$ phase of the cell cycle (Figure 4).

\section{Activation of MAP Kinase Pathway}

MAP kinase is a key element of signal transduction pathways involved in the regulation of cell growth induced by epidermal growth factor and insulin-like growth factor. To 
A
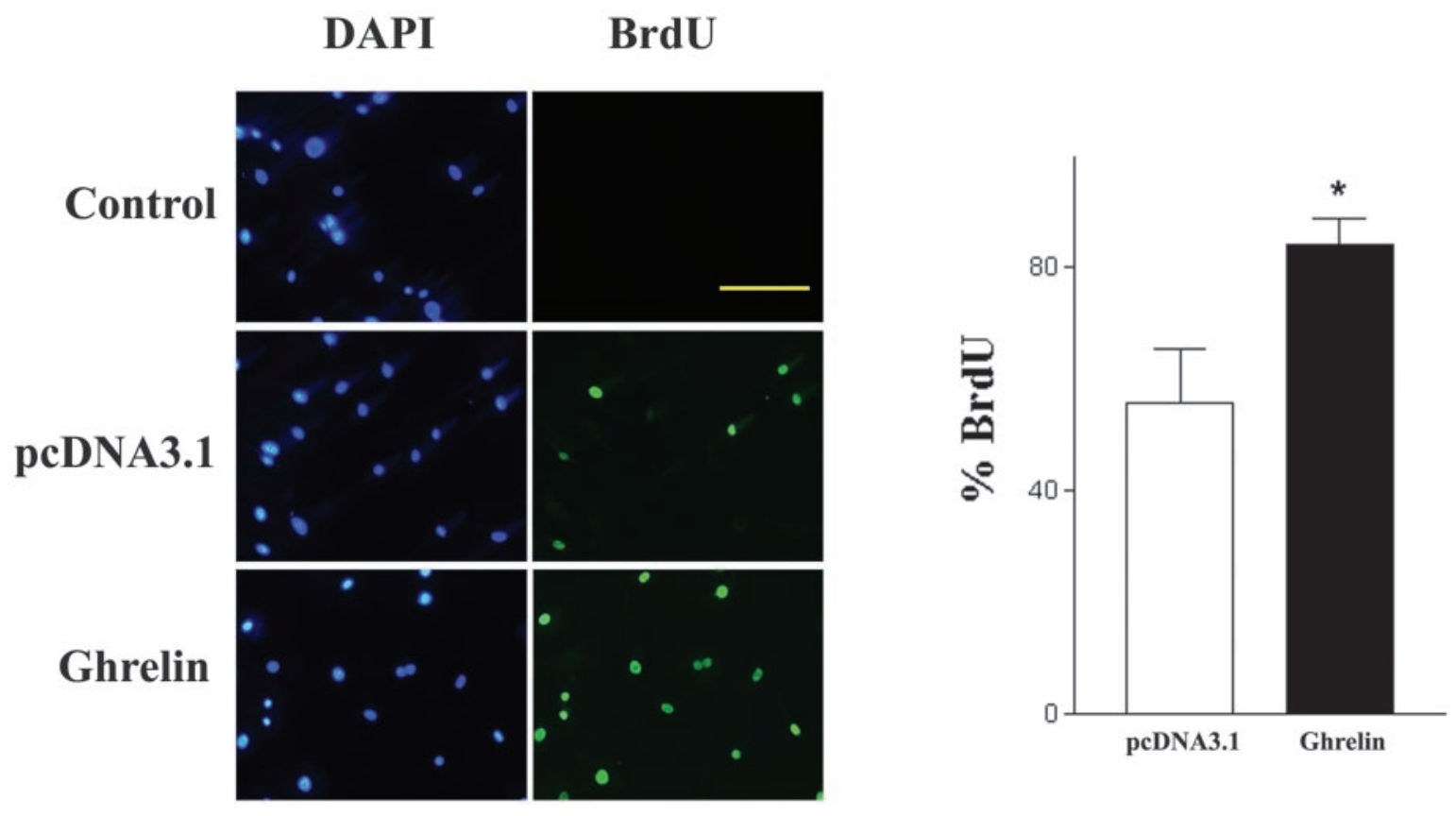

B
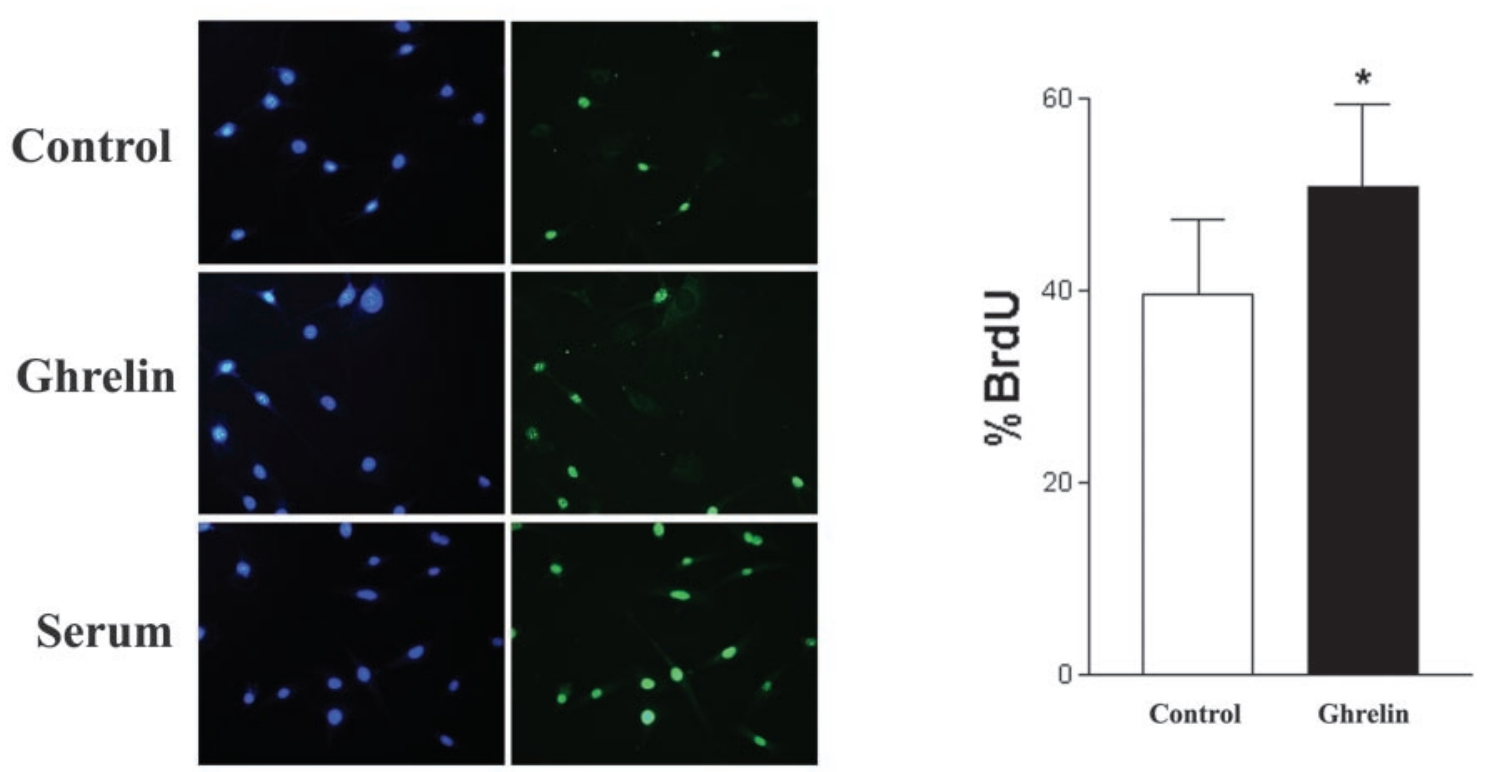

Figure 3. Effect of ghrelin on cell proliferation. Cells were treated with BrdU $(10 \mu \mathrm{g} / \mathrm{ml})$ for $24 \mathrm{~h}$ and labeled with an antibody against for BrdU. Nuclei were counterstained with 4,6-diamidino-2-phenylindole. BrdU-positive cells were counted under an epifluorescent microscope. (A) Cells overexpressing vector pcDNA3.1 or ghrelin. (B) Native 3T3-L1 cells treated with exogenous ghrelin (1 $\mu \mathrm{M})$ for $24 \mathrm{~h}$. Data are representative of four to five independent experiments. ${ }^{*} \mathrm{p}<0.05$. Bar, $100 \mu \mathrm{m}$.

determine whether MAP kinase is involved in the signal transduction of cell growth triggered by ghrelin, we treated 3T3-L1 cells with ghrelin $\left(10^{-6} \mathrm{M}\right)$. Phosphorylated MAP kinase proteins were analyzed using a specific antibody targeting phospho-p44/42 MAP kinase (extracellular signalregulated kinase 1 and 2). As shown in Figure 5, exposure of 3T3-L1 cells to ghrelin activated the phosphorylation of
MAP kinase. This phosphorylation of MAP kinase occurred as early as $5 \mathrm{~min}$ after ghrelin stimulation, reached the maximum in $10 \mathrm{~min}$, and returned to baseline in $15 \mathrm{~min}$.

\section{Inhibition of PPAR- $\gamma$}

PPARs are a family of transcription factors that function cooperatively to activate adipocyte genes and thereby bring 


\section{pcDNA3.1}
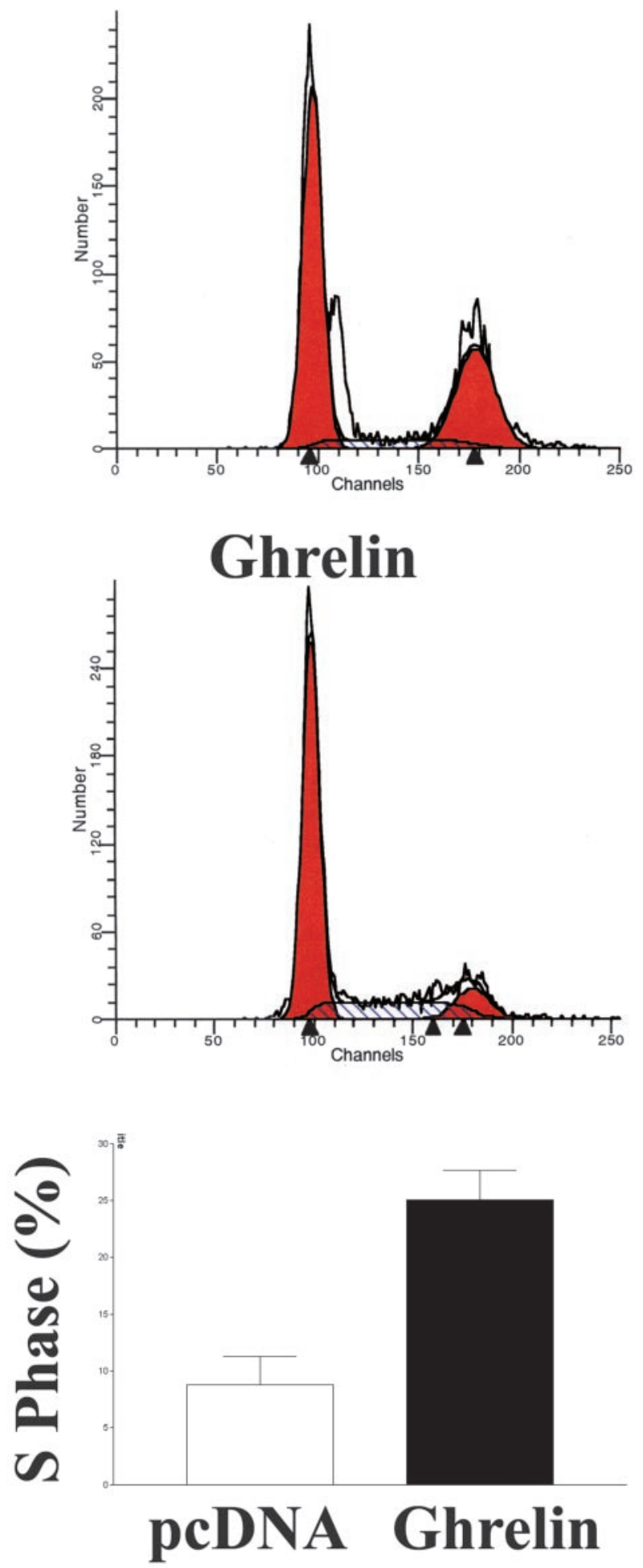

Figure 4. Analysis of cell cycle by flow cytometry. Cells overexpressing ghrelin or pcDNA3.1 were harvested after culturing for $48 \mathrm{~h}$, stained with propidium iodide in hypotonic lysis buffer, and analyzed by flow cytometry. DNA histogram was deconvoluted, and percentage of cells in each phase of cell cycle was calculated and expressed as mean \pm SEM. Results are representative of four separate experiments. ${ }^{*} \mathrm{p}<0.05$.

\section{Ghrelin}

\section{$\begin{array}{lllllllll}0 & 0.5 & 1 & 2 & 5 & 10 & 15 & 30 & \text { min }\end{array}$}

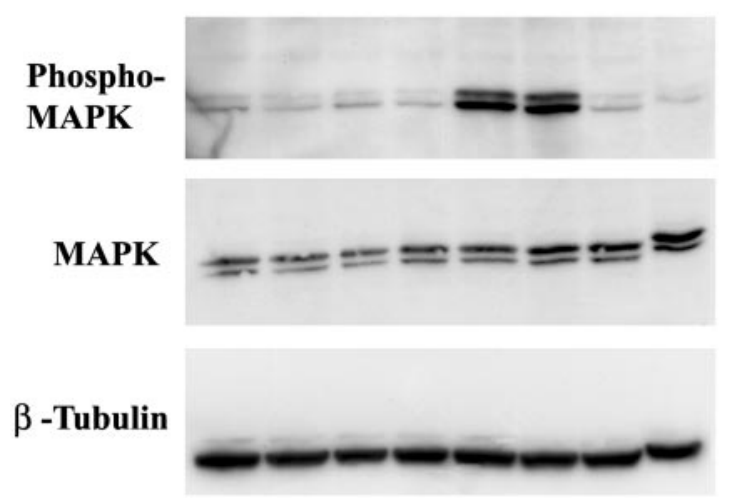

Figure 5. Activation of MAP kinase by ghrelin. 3T3-L1 cells were treated with ghrelin $\left(10^{-6} \mathrm{M}\right)$ or control medium for the time indicated. Cell lysates containing $50 \mu \mathrm{g}$ of protein were loaded into SDS-polyacrylamide gel, transferred to membranes, and probed with a specific antibody that recognizes phosphorylated MAP kinase. Membranes were then stripped and reprobed with antibodies against nonphosphorylated MAP kinase and $\beta$-tubulin separately. Similar findings were observed in three separate experiments.

about adipocyte differentiation. It is commonly used as a marker of adipocyte differentiation (Gregoire et al., 1998). To test whether PPAR- $\gamma$ is involved in the ghrelin-mediated inhibition of adipogenesis, PPAR- $\gamma$ was assayed using specific antibody recognizing PPAR- $\gamma 1$ and PPAR- $\gamma 2$. In 3T3-L1 cells expressing vector pcDNA3.1, negligible PPAR- $\gamma$ protein was observed in day 0; expression was first detected in day 1 and reached peak values at day 4 (Figure 6A). The level of PPAR- $\gamma$ protein was greatly inhibited in cells overexpressing ghrelin (Figure 6A). As shown in Figure 6B, cells overexpressing ghrelin demonstrated negligible expression of PPAR- $\gamma 2$ mRNA until day 4 of cell differentiation, whereas PPAR- $\gamma 2$ mRNA was constantly expressed in control cells from day 1 to day 5 of cell differentiation.

\section{Receptor-mediated Effect of Ghrelin}

Ligand binding studies of radiolabeled ghrelin were performed on 3T3-L1 cells. Dose-dependent displacement of ${ }^{125} \mathrm{I}$-ghrelin by ghrelin was observed for wild-type 3T3L-1 cells, 3T3L-1 cells transfected with pcDNA3.1 (control), and 3T3L-1 cells transfected with the pcDNA3.1 vector containing the ghrelin cDNA (Figure 7). In contrast, des-octanoyl ghrelin was incapable of displacing ${ }^{125} \mathrm{I}$-ghrelin from wildtype 3T3L-1 cells and no specific binding of ${ }^{125}$ I-des-octanoyl ghrelin was observed in those cells. This observation confirmed that ${ }^{125} \mathrm{I}$-ghrelin recognized a single class of highaffinity, saturable, and specific binding sites and that the endogenous 3T3L-1 cell ghrelin receptor requires an acylated ghrelin for binding. The receptor protein expression level $\left(B_{\max }\right)$ and binding affinity $\left(K_{\mathrm{i}}\right)$ for native and transfected 3T3-L1 cells are summarized in Table 1.

To determine whether the previously identified ghrelin receptor is expressed in 3T3-L1 preadipocytes, we assayed the expression of ghrelin receptor mRNA by RT-PCR by using different pairs of primers from the published ghrelin receptor cDNA sequence. As shown in Figure 8, no expression of ghrelin receptor mRNA was detected in 3T3-L1 cells, whether cells were undifferentiated or differentiated into 
A

Days of Differentiation

$\begin{array}{llllll}0 & 1 & 2 & 3 & 4 & 5\end{array}$

pcDNA3.1

Ghrelin

B

\section{Days of Differentiation}

$\begin{array}{llllll}0 & 1 & 2 & 3 & 4 & 5\end{array}$

pcDNA3.1

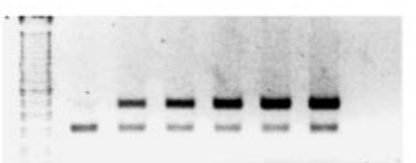

Ghrelin

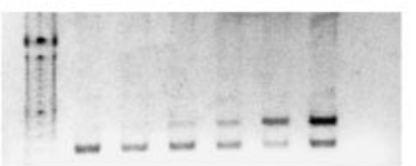

PPAR- $\gamma$ $\beta$-actin

PPAR- $\gamma$ $\beta$-actin

Figure 6. Inhibition of PPAR- $\gamma$ expression by ghrelin. Cells overexpressing ghrelin or pcDNA3.1 were harvested from day 0 to 5. (A) Equivalent amount of cell lysates were loaded and were analyzed by Western blotting. PPAR- $\gamma$ proteins were detected with PPAR antibodies from Santa Cruz Biotechnology (1:200). Results are representative of four individual experiments. (B) Total RNA was extracted from cultured cells at the time indicated. RT-PCR was performed using PPAR- $\gamma 2$ primers. Blot shown is the typical of four separate experiments.

adipocytes, whereas positive signals were readily detected from the hypothalamus. These data suggest that the previously identified ghrelin receptor is not expressed in 3T3-L1 cells and indicate that a novel ghrelin receptor subtype may mediate the effect of ghrelin on 3T3-L1 cell proliferation and differentiation.

\section{DISCUSSION}

The present study demonstrates that ghrelin regulates proliferation and differentiation of preadipocytes, likely via a

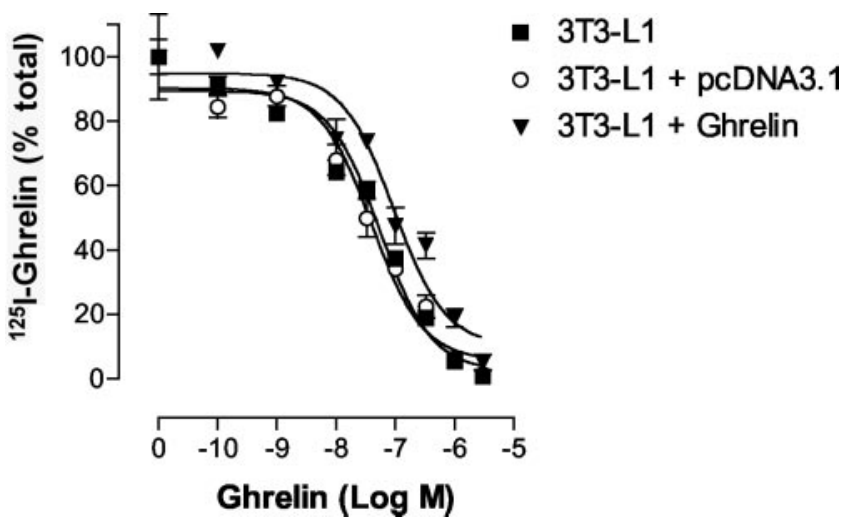

Figure 7. ${ }^{125} \mathrm{I}$-ghrelin displacement. Displacement of ${ }^{125} \mathrm{I}$-ghrelin by ghrelin on wild-type 3T3L-1 cells, 3T3L-1 cells transfected with pcDNA3.1 vector, and 3T3L-1 cells transfected with pcDNA3.1 containing the rat ghrelin cDNA.

Table 1. $K_{1}$ of ${ }^{125} \mathrm{I}$-ghrelin and $B_{\max }$ of ghrelin receptor $(\mathrm{n}=3)$

\begin{tabular}{lcc}
\hline & $K_{\mathrm{i}}(\mathrm{nM})$ & $\begin{array}{c}B_{\max }(\mathrm{fmol} / \mathrm{mg} \\
\text { protein) }\end{array}$ \\
\hline 3T3-L1 & $45.1 \pm 2.2$ & $10.4 \pm 0.2$ \\
3T3-L1 + pcDNA3.1 & $41.0 \pm 11.4$ & $9.0 \pm 1.4$ \\
3T3-L1 + ghrelin & $96.2 \pm 11.1$ & $8.6 \pm 0.2$ \\
\hline
\end{tabular}

novel unidentified ghrelin receptor subtype. The data that support this conclusion are fivefold: 1) cells overexpressing ghrelin demonstrated significant decreased adipogenesis; 2) both exogenous ghrelin and ghrelin overexpression stimulated preadipocyte proliferation; 3) ghrelin activated an intracellular signaling pathway involving MAP kinase; 4) transcription and translation of PPAR- $\gamma$ were attenuated in cells overexpressing ghrelin; and 5) ghrelin binding activity was demonstrated by radiolabeled ghrelin, whereas RT-PCR by using primer sequences of the previously identified ghrelin receptor was negative.

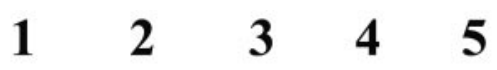

\section{GHSR}

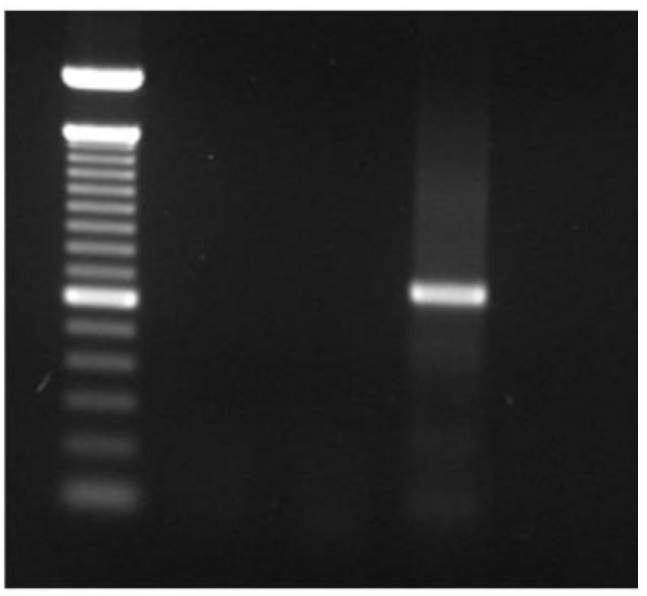

\section{$\beta$-actin}

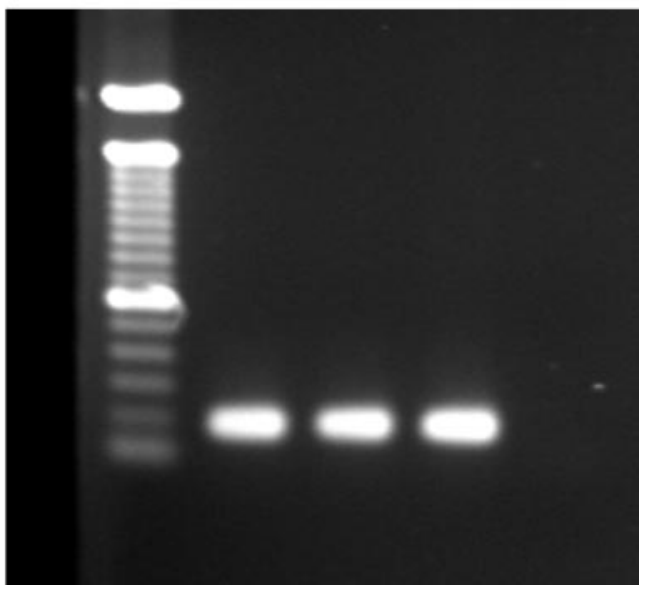

Figure 8. No expression of known ghrelin receptor mRNA in 3T3-L1 cells. RT-PCR was performed on total RNA extracted from undifferentiated and differentiated 3T3-L1 cells with primers specific for the known ghrelin receptor (top) or $\beta$-actin (bottom). Lane 1, marker; lane 2, undifferentiated 3T3-L1 cells; lane 3, 3T3-L1 cells differentiated for $10 \mathrm{~d}$; lane 4 , positive control with RNA from hypothalamus; and lane 5, negative control. 
Ghrelin is a potent orexigenic hormone that plays a role in appetite stimulation and energy homeostasis. Previous studies have suggested that the effect of ghrelin in the regulation of feeding behavior and energy metabolism is mediated by a direct hypothalamic mechanism. Expression of ghrelin in the hypothalamic neurons has been demonstrated (Cowley et al., 2003). Ghrelin receptor and ghrelin binding have also been identified on presynaptic terminals of neuropeptide $Y$ (NPY) neurons (Cowley et al., 2003), and ghrelin activation of arcuate NPY neurons has been demonstrated by electrophysiological recording (Cowley et al., 2003). Peripheral ghrelin increases the expression of immediate early genes in the medial arcuate nucleus, an area rich in NPY/AGRP (agouti-related protein) neurons (Hewson and Dickson, 2000; Wang et al., 2002). Administration of ghrelin activates NPY neurons and stimulates the expression of NPY and AGRP mRNA in the hypothalamus. The orexigenic effect of ghrelin is blocked by antibodies of NPY and AGRP, and their receptor antagonists (Nakazato et al., 2001). The influence of ghrelin on NPY and AGRP pathways seems to be counteracting the action of leptin (Nakazato et al., 2001). These observations suggest that the coactivation of NPY and AGRP pathways in hypothalamus by ghrelin plays a role in appetite stimulation and energy homeostasis. The current results demonstrate a direct effect of ghrelin on adipocytes. This finding is consistent with recent studies demonstrating expression of a putative ghrelin receptor subtype 1a on adipocytes (Choi et al., 2003). Functional studies by Ott et al. (2002) and Choi et al. (2003) have shown that ghrelin upregulates expression of adipokine and the GAPDG activity in adipocytes by a direct peripheral mechanism.

As the only known orexigenic hormone, ghrelin participates not only in meal patterning (Cummings et al., 2001) but also in long-term body weight regulation (Tschop et al., 2000; Wren et al., 2000; Nakazato et al., 2001). The adipogenic effect of ghrelin is suggested by in vivo studies showing that chronic administration of ghrelin increases body weight by reducing metabolic rate and fat catabolism (Tschop et al., 2000). However, in vitro studies characterizing the direct effect of ghrelin on adipogenesis have been inconsistent. Choi et al. (2003) have shown that exogenous ghrelin stimulates adipogenesis in primary culture of rat preadipocytes, whereas Ott et al. (2002) reported that chronic treatment of SV40 large $\mathrm{T}$ antigen-immortalized brown adipocytes with ghrelin had no effect on adipogenesis. Using a stable cell line overexpressing ghrelin, we demonstrate that ghrelin inhibits adipogenesis in 3T3-L1 preadipocytes.

In the central nervous system, ghrelin receptor subtype 1a is predominantly present (Guan et al., 1997). The subtype of ghrelin receptor expressed in peripheral tissue is less well characterized. Whereas ghrelin receptor subtype 1a has been reported to be present in a variety of peripheral tissues, recent studies by Cassoni et al. (2000) and Baldanzi et al. (2002) have suggested the presence of a novel, as-yet-unidentified subtype of ghrelin receptor, distinct from the ghrelin receptor subtype 1a. Our findings also suggest that a novel subtype of ghrelin receptor may be present on 3T3-L1 cells. Although no expression of ghrelin receptor 1a mRNA was detected in 3T3-L1 cells by RT-PCR, ghrelin recognized a high-affinity binding site on 3T3-L1 cells. The binding of radiolabeled ghrelin could be competitively displaced with unlabeled ghrelin, with an affinity constant comparable with that of ghrelin receptor $1 \mathrm{a}$ as measured on pituitary and hypothalamus membranes. The ghrelin receptor on 3T3-L1 cells required an acylated ghrelin for binding. This characteristic distinguishes it from the ghrelin receptor subtype described by Baldanzi et al. (2002) on H9c2 cardiomyocytes, in which a common single class of binding sites was recognized by both ghrelin and des-acyl-ghrelin, with an affinity constant that was 10-fold higher. The presence of diverse ghrelin receptor subtypes in peripheral tissues may explain the discrepant results in various cell models. Using primary culture of rat preadipocytes, Choi et al. (2003) reported that ghrelin stimulates adipogenesis by activation of the ghrelin receptor subtype 1a. In contrast, Ott et al. (2002) demonstrated that ghrelin did not affect the pattern or extent of fat accumulation in a well-characterized brown adipocyte model despite direct inhibition of adiponectin gene expression. The subtype of ghrelin receptor in brown adipocytes was not characterized.

Ghrelin exposure stimulates proliferation in 3T3-L1 cells. Three pieces of evidence support the mitotic effect of ghrelin in 3T3-L1 preadipocytes: 1) acute stimulation by exogenous ghrelin significantly increased BrdU incorporation; 2) cells overexpressing ghrelin demonstrate increased proliferation as measured by cell number and BrdU incorporation; and 3) cell cycle analysis by flow cytometry shows a significantly increased percentage of S-phase cells in ghrelin-overexpressing cells. Because growth arrest is a prerequisite for adipocyte differentiation (Gregoire et al., 1998), it is presumed that the mitotic activity of ghrelin inhibits growth arrest and therefore prevents the progression of adipocyte differentiation. This concept is supported by the observation that PPAR $-\gamma$ transcription and translation are significantly attenuated in cells overexpressing ghrelin. PPAR- $\gamma$ has been shown to induce growth arrest in fibroblasts and in adipogenic SV40 large T antigen-transformed cells (Hu et al., 1995; Altiok et al., 1997).

A number of growth factors, including epidermal growth factor, platelet-derived growth factor, and basic fibroblast growth factor, inhibit the conversion of preadipocytes into adipocytes (Gregoire et al., 1998). An MAP kinase-dependent pathway may be important in ghrelin-mediated regulation of preadipocyte proliferation and differentiation because ghrelin activates the phosphorylation of MAP kinase. Previously, Camp and Tafuri (1997)) and $\mathrm{Hu}$ et al. (1996) have shown that phosphorylation of MAP kinase leads to down-regulation of PPAR- $\gamma$, a master coordinator of the adipocyte differentiation process. Based on observations that ghrelin stimulates phosphorylation of MAP kinase and attenuates PPAR- $\gamma$ expression, we propose that ghrelin inhibits PPAR- $\gamma$ activity via the mediation of MAP kinase to prevent adipocyte differentiation in 3T3-L1 cells.

In summary, our study demonstrates that ghrelin stimulates preadipocyte cell proliferation and inhibits adipogenesis via the mediation of a novel ghrelin receptor subtype. Activation of this ghrelin receptor subtype leads to a sequence of intracellular signaling involving phosphorylation of the MAP kinase and down-regulation of PPAR- $\gamma$ activity.

\section{REFERENCES}

Altiok, S.M., Xu, M., and Spiegelman, B.M. (1997). PPARgamma induces cell cycle withdrawal: inhibition of E2F/DP DNA-binding activity via downregulation of PP2A. Genes Dev. 11, 1987-1998.

Baldanzi, G., et al. (2002). Ghrelin and des-acyl ghrelin inhibit cell death in cardiomyocytes and endothelial cells through ERK1/2 and PI 3-kianse/ AKT. J. Cell Biol. 159, 1029-1037.

Banks, W.A., Tschop, M., and Heiman, M.L. (2002). Extent and direction of ghrelin transport across the blood brain barrier is determined by its unique primary structure. J. Pharmacol. Exp. Ther. 302, 822-827.

Camp, H.S., and Tafuri, S.R. (1997). Regulation of peroxisome proliferatorsactivated receptor $\gamma$ activity by mitogen-activated protein kinase. J. Biol Chem. 272, 10811-10816. 
Cassoni, P., Papotti, M., Ghe, C., Catapano, F., Sapino, A., Graziani, A., Deghenghi, R., Reissmann, T., Ghigo, E., and Muccioli, G. (2000). Identification, characterization, and biological activity of specific receptors for natural (ghrelin) and synthetic growth hormone secretagogues and analogs in human breast carcinomas and cell lines. J. Clin. Endocrinol. Metab. $86,1738-1745$.

Choi, K., Roh, S.-G., Hong, Y-H., Shrestha, Y.B., Hishikawa, D., Chen, C., Kojima, M., Kangawa, K., and Sasaki, S.-I. (2003). The role of ghrelin and growth hormone secretagogues receptor on rat adipogenesis. Endocrinology $144,754-759$.

Cowley, M.A., et al. (2003). The distribution and mechanism of action of ghrelin in the CNS demonstrates a novel hypothalamic circuit regulating energy homeostasis. Neuron 37, 649-661.

Cummings, D.E., Purnell, J.Q., Frayo, R.S., Schmidova, K., Wisse, B.E., and Weigle, D.S. (2001). A preprandial rise in plasma ghrelin levels suggests a role in meal initiation in humans. Diabetes 50, 1714-1719.

Date, Y., Kojima, M., Hosoda, H., Sawaguchi, A., Mondal, M.S., Suganuma, T., Matsukura, S., Kangawa, K., and Nakazato, M. (2000). Ghrelin, a novel growth hormone-releasing acylated peptide, is synthesized in a distinct endocrine cell type in the gastrointestinal tracts of rats and humans. Endocrinology 141, 4255-4261.

Date, Y., et al. (2002). Ghrelin is present in pancreatic alpha-cells of humans and rats and stimulates insulin secretion. Diabetes 51, 124-9.

Guan, X-M., Yu, H., Palyha, O.C., McKee, K.K., Feighner, S.D., Sirinathsinghji, D.J.S., Smith, R.G., Van der Ploeg, L.H.T., and Howard, A.D. (1997). Distribution of mRNA encoding the growth hormone secretagogue receptor in brain and peripheral tissues. Mol. Brain Res. 48, 23-29.

DeBlasi, A., O'Reilley, K., and Motulsky, H.J. (1989). Calculating receptor number from binding experiments using same compound as radioligand and competitor. Trends Pharmacol. Sci. 10, 227-229.

Gregoire, F.M., Smas, C.M., and Sul, H.S. (1998). Understanding adipocyte differentiation. Physiol. Rev. 78, 783-809.

Hewson, A.K., and Dickson, S.L. (2000). Systemic administration of ghrelin induces fos and Egr-1 proteins in the hypothalamic arcuate nucleus of fasted and fed rats. J. Neuroendocrinol. 12, 1047-1049.

Horvath, T.L., Diano, S., sotonyi, P., Heiman, M., and Tschop, M. (2001). Minireview: ghrelin and the regulation of energy balance-a hypothalamic perspective. Endocrionolgy 142, 4163-4169.

Howard, A.D., et al. (1996). A receptor in pituitary and hypothalamus that functions in growth hormone release. Science 273, 974-977.

Hu, E., Kim, J.B., Sarraf, P., and Spiegelman, B.M. (1996). Inhibition of adipogenesis through MAP kinase-mediated phosphorylation of PPARgamma. Science 274, 2100-3.
Hu, E., Tontonoz, P., and Speigelman, B.M. (1995). Trans-differentiation of myoblasts by the adipogenic transcription factors PPAR gamma and C/EBP alpha. Proc. Natl. Acad. Sci. USA 92, 9856-9860.

Lee, H-M., Wang, G., Englander, E.W., Kojima, M., and Greeley, G.H., Jr. (2002). Ghrelin, a new gastrointestinal endocrine peptide that stimulates insulin secretion: enteric distribution, ontogeny, influence of endocrine and dietary manipulations. Endocrinology 143, 185-190.

Kojima, M., Hosoda, H., Date, Y., Nakazato, M., Matsuo, H., and Kangawa, K (1999). Ghrelin is a growth-hormone-releasing acylated peptide from stomach. Nature 402, 656-60.

McKee, K.K., Palyha, O.C., Feighner, S.D., Hreniuk, D.L., Tan, C.P., Phillips, M.S., Smith, R.G., van der Ploeg, L.H.T., and Howard, A.D. (1997). Molecular analysis of rat pituitary and hypothalamic growth hormone secretagogue receptors. Mol. Endocrinol. 11, 415-423.

Mori, K., et al. (2000). Kidney produces a novel acylated peptide, ghrelin. FEBS Lett. 486, 213-6.

Nakazato, M. Murakami, N., Date, Y., Kojima, M., Matsuo, H., Kangawa, K. and Matrukura, S. (2001). A role for ghrelin in the central regulation of feeding. Nature 409, 194-198.

Ott, V., Fasshauer, M., Dalski, A., Meier, B., Perwitz, N., Klein, H.H., Tschop, M., and Klein, J. (2002). Direct peripheral effects of ghrelin include suppression of adiponectin expression. Horm. Metab. Res. 34, 640-645.

Ross, S.E., Hemati, N., Longo, K.A., Bennet, C.N., Lucas, P.C., Erickson, R.L., and MacDougald, O.A. (2000). Inhibition of adipogenesis by Wnt signaling. Science 289, 950-953.

Takaya, K., et al. (2000) Ghrelin strongly stimulates growth hormone release in humans. J. Clin. Endocrinol. Metab. 85, 4908-4911.

Toshinai, K., Mondal, M.S., Nakazato, M., Date, Y., Murakami, N., Kojima, M., Kangawa, K., and Matsukura, S. (2001). Upregulation of ghrelin expression in the stomach upon fasting, insulin-induced hypoglycemia, and leptin administration. Biochem. Biophys. Res. Commun. 281, 1220-1225.

Tschop, M., Smiley, D.L., and Heiman, M.L. (2000). Ghrelin induces adiposity in rodents. Nature 407, 908-13.

Wang, L., Saint-Pierre, D.H., and Tache, Y. (2002). Peripheral ghrelin selectively increases fos expression in neuropeptide Y-synthesizing neurons in mouse hypothalamic arcuate nucleus. Neurosci. Lett. 325, 47-51.

Weiss, G.H., Rosen, O.M., and Rubin, C.S. (1980). Regulation of fatty acid synthetase concentration and activity during adipocyte differentiation. J. Biol Chem. 255, 4751-4757.

Wren, A.M., et al. (2000). The novel hypothalamic peptide ghrelin stimulates food intake and growth hormone secretion. Endocrinology 141, 4325-8.

Yang, Y.K., Fong, T.M., Dickinson, C.J., Mao, C., Li, J.Y., Tota, M.R., Mosley, R., Van der Ploeg, L.H., and Gantz, I. (2000). Molecular determinants of ligand binding to the human melanocortin-4 receptor. Biochemistry 39, 14900-14911. 